\section{OP0117 MICRO-STRUCTURAL CHANGES ASSOCIATED WITH ANTI-CITRULLINATED VIMENTIN AUTOIMMUNITY IN RA-AT-RISK INDIVIDUALS PRECIPITATE THE ONSET OF RHEUMATOID ARTHRITIS}

Arnd Kleyer ${ }^{1}$, David Simon ${ }^{1}$, Cong Duy Bui', Axel Hueber ${ }^{1}$, Holger Bang ${ }^{2}$, Andreas Ramming ${ }^{1}$, Jürgen Rech ${ }^{1}$, Gerhard Krönke ${ }^{1}$, Georg Schett ${ }^{1} .{ }^{1}$ FriedrichAlexander University Erlangen-Nuremberg (FAU) and Universitätsklinikum Erlangen, Department of Internal Medicine 3, Rheumatology and Immunology, 91054 Erlangen, Germany, ${ }^{2}$ Orgentec Diagnostika, 55129 Mainz, Germany

Background: Development of rheumatoid arthritis (RA) is characterized by a several years lasting phase of autoimmunity, characterized by the presence of anti-modified protein antibodies (AMPA), recognizing citrullinated, carbamylated or acetylated proteins, as well as rheumatoid factor (RF) which precedes the onset of clinical disease $(1,2)$. High resolution peripheral quantitative (HR-pQCT) technique enables the depiction of small cortical changes in peripheral joints (3).

Objectives: To describe microstructural bone lesions in rheumatoid arthritis (RA) at-risk individuals using HR-pQCT technique, their relation to rheumatoid arthritis specific autoimmunity, particularly osteoclast-inducing citrullinated vimentin (cVIM) antibodies and their impact on the later development of RA.

Methods: Cortical micro-channels (CoMiCs) as well as volumetric cortical and trabecular bone densities were analyzed by high-resolution computed tomography in the hand joints of RA at-risk individuals. Anti-modified protein antibody (AMPA) response was profiled including reactivities against citrullinated proteins (vimentin, enolase, fibrinogen) as well as carbamylated and acetylated vimentin. All subjects were followed for the development of RA.

Results: RA at-risk subjects (all $\mathrm{N}=75$ ) with high-level (>1000U) CVIM antibodies showed a broader AMPA response and significantly more severe microstructural changes (higher CoMiCs, lower cortical and trabecular bone volume) compared to subjects with low/no cVIM reactivity. High cVIM antibodies and microstructural changes ( $>15$ radial CoMiCs/joint) were associated with the presence of arthralgia. Furthermore, progression to RA was high in subjects with high cVIM (53\%) vs. those with low $(22 \%)$ or no $(5 \%)$ antibodies and those with microstructural changes (46\%) vs. those without such changes (16\%).

Conclusion: CVIM antibodies are associated to microstructural changes in RA atrisk individuals and predict the onset of RA. These data support the concept of structural priming of joints by autoimmunity before the onset of RA

\section{REFERENCES:}

[1] McInnes IB, Schett G. The pathogenesis of rheumatoid arthritis. N Engl J Med. 2011;365:2205-19.

[2] Catrina Al, Svensson Cl, Malmström V, Schett G, Klareskog L. Mechanisms leading from systemic autoimmunity to joint-specific disease in rheumatoid arthritis. Nat Rev Rheumatol. 2017;13:79-86.

[3] Werner D, Simon D, Englbrecht M, et al. Early Changes of the Cortical Micro-Channel System in the Bare Area of the Joints of Patients With Rheumatoid Arthritis. Arthritis Rheumatol. 2017;69:1580-7.

Disclosure of Interests: Arnd Kleyer Grant/research support from: Lilly, Consultant for: Lilly, Speakers bureau: Abbvie, David Simon Grant/research support from: Novartis, Consultant for: Lilly, Speakers bureau: Janssen, Cong Duy Bui: None declared, Axel Hueber Grant/research support from: Novartis, Pfizer, Consultant for: Lilly, Speakers bureau: Lilly, Novartis, Janssen, Abbvie, Holger Bang Employee of: Dr. Bang is employee of the diagnostic company Orgentec Diagnostika., Andreas Ramming Grant/research support from: Novartis, Jürgen Rech Grant/research support from: Bristol-Myers Squibb and Celgene (greater than $\$ 10,000)$, Consultant for: Bristol-Myers Squibb, Celgene, Chugai, GlaxoSmithKline, Janssen, Eli Lilly, Novartis, Roche, Sanofi Aventis, and UCB (in total more than $\$ 10,000$ ), Speakers bureau: Bristol-Myers Squibb, Celgene, Chugai, GlaxoSmithKline, Janssen, Eli Lilly, Novartis, Roche, Sanofi Aventis, and UCB (in total more than $\$ 10,000$ ), Gerhard Krönke Grant/research support from: Lilly, Pfizer, Speakers bureau: Novartis, Georg Schett: None declared DOI: 10.1136/annrheumdis-2019-eular.4638

\section{OP0118 \\ DISCRETE PATTERNS OF CITRULLINATED PEPTIDE AUTOANTIBODY REACTIVITIES EMERGE DURING PROGRESSION FROM PRE-DISEASE STATE TO DIAGNOSIS OF RHEUMATOID ARTHRITIS}

Matthew J Loza ${ }^{1}$, Sunil Nagpal ${ }^{1}$, Renee Laird ${ }^{2}$, Suzanne Cole ${ }^{1}$, Frederic Baribaud $^{1}$, lan Anderson ${ }^{1}$, Navin Rao ${ }^{1}$, Mark Riddle ${ }^{3}$, Chad Porter ${ }^{2}$ ${ }^{1}$ Janssen Research and Development, LLC, Spring House, PA, United States of America; ${ }^{2}$ Navy Medical Research Center, Enteric Diseases Department, Silver Springs, MD. United States of America; ${ }^{3} F$. Edward Hebert School of Medicine, Uniformed Services University, Bethesda, MD, United States of America

Background: Rheumatoid Arthritis (RA) patients with established disease can have autoantibodies reactive to a broad array of citrullinated antigens.
Autoantibodies reactive against several citrullinated proteins can develop 10-15 years before the clinical onset of disease.

Objectives: We aimed to identify common patterns of citrullinated peptide reac tivities that emerge among subjects during progression from a pre-disease state through diagnosis of RA.

Methods: 500 subjects with RA (based on ICD9-CM code) were identified from the Defense Medical Surveillance System. For each subject, up to four serum samples were obtained from the Department of Defense (DoD) serum repository: 1 from earliest time point before diagnosis $(9.2 \pm 2.0$ years before, mean $\pm S D$ ); one proximal to (immediately prior to or after) disease diagnosis ( $127 \pm 125$ days before diagnosis); plus 2 intermediate time points. A discovery subset of serum samples from 88 RA subjects confirmed to be positive for anti-citrullinated protein antibodies (ACPA) at the diagnosis-proximal time point ( $>5 \mathrm{U} / \mathrm{mL}$ for cyclic citrullinated peptide (CCP)-II test) was assessed for IgG antibodies to 36 antigens (24 citrullinated-peptide antigens among 14 proteins and 12 non-citrullinated antigens among 9 proteins) using a custom Luminex-based assay. Subjects testing above the upper limit of detection for the CCP-II test $(300 \mathrm{U} / \mathrm{mL})$ were considered ACPA high $(n=28)$, with the remainder considered moderate $(n=60)$.

Results: For the group of ACPA-high subjects at the diagnosis-proximal time point, average lgG autoantibody binding to 9 citrullinated peptide antigens (from 7 proteins: clusterin, enolase, fibrinogen $A$, fibrinogen $B$, fibronectin, filaggrin vimentin) showed significant increase from the earliest through diagnosis-proximal time points at the population level (FDR<0.05). In ACPA-moderate subjects, IgG levels to only one antigen (citrullinated-fibronectin) had a nominally significan but small increase (mean $+8 \%$ ) during this time frame. Significant reactivity to the non-citrullinated antigens was not observed. In ACPA -high but not -moderate subjects, group averages for a composite score of the 9 citrullinated peptide antigens increased relative to the earliest time points, with increased average levels observable 6-years before diagnosis that steadily increased as approaching diagnosis. Patterns of increases in IgG to specific citrullinated peptides differed among subjects, for both ACPA -high and -moderate groups. In the ACPA-high group, $46 \%$ of subjects had $\geq 50 \%$ increase in a majority $(\geq 5)$ of the 9 citrullinated-peptide antigen set and the remaining had $\geq 50 \%$ increase for at least 1 of the antigens. In contrast, in the ACPA-moderate group, $58 \%$ of subject did not achieve $\geq 50 \%$ increase for any of the 9 antigens and only $8 \%$ of subjects had $\geq 50 \%$ increase in a majority of the 9-antigen set. The most commonly increased lgG reactivities were for citrullinated -filaggrin and -fibrinogen $A$, with $\geq 50 \%$ increase in $64 \%$ of ACPA-high and $20 \%$ of ACPA-moderate subjects.

Conclusion: Novel patterns of citrullinated peptide autoantibody reactivities that begin to emerge on average about 6 years before diagnosis of RA have been identified in samples from the US DoD serum repository. Evaluation of specific anti-citrullinated peptide autoantibodies could potentially provide sensitive patient-tailored biomarkers to monitor disease trajectories as at-risk individuals progress to clinically-defined RA.

Disclosure of Interests: : Matthew J Loza Shareholder of: Johnson \& Johnson, Employee of: Janssen Research \& Development, LLC, Sunil Nagpal Shareholde of: Johnson \& Johnson, Employee of: Janssen Research \& Development, LLC Renee Laird: None declared, Suzanne Cole Shareholder of: Johnson \& Johnson, Employee of: Janssen Research \& Development, LLC, Frederic Baribaud Shareholder of: Johnson \& Johnson, Employee of: Janssen Research \& Development, LLC, Ian Anderson Shareholder of: Johnson \& Johnson, Employee of: Janssen Research \& Development, LLC, Navin Rao Shareholder of: Johnson \& Johnson, Employee of: Janssen Research \& Development, LLC, Mark Riddle: None declared, Chad Porter: None declared

DOI: 10.1136/annrheumdis-2019-eular.3399

\section{OP0119 THE PRE-TREATMENT GUT MICROBIOME PREDICTS EARLY RESPONSE TO RHEUMATOID ARTHRITIS THERAPY}

Sandrine Isaac ${ }^{1}$, Alejandro Artacho ${ }^{1}$, Renuka Nayak ${ }^{2}$, Alejandra Flor ${ }^{1}$, Steven Abramson ${ }^{3}$, Pamela Rosenthal ${ }^{3}$, Leonor Puchades ${ }^{4}$, Andrew Patterson ${ }^{5}$, Antonio Pineda-Lucena ${ }^{6}$, Peter Turnbaugh ${ }^{2}$, Carles Ubeda $^{1}$, Jose Scher ${ }^{3}$. ${ }^{1}$ FISABIO, Valencia, Spain; ${ }^{2}$ University of California, San Francisco, United States of America; ${ }^{3}$ New York University, New York, United States of America; ${ }^{4}$ Centro de Investigación Príncipe Felipe, Valencia, Spain; ${ }^{5}$ Penn State University, Pennsylvania, United States of America; ${ }^{6}$ Instituto de Investigación Sanitaria La Fe, Valencia, Spain

Background: Early treatment initiation in rheumatoid arthritis (RA) is fundamental to avoid chronic joint destruction and disability. Despite remarkable advances in RA therapeutics, oral methotrexate (MTX) remains the anchor drug and mainstay of treatment worldwide $(1,2)$. However, MTX bioavailability has a wide inter-individual variability and $>50 \%$ of patients with moderate or severe RA show no or suboptimal improvement in their symptoms in response to $\operatorname{MTX}(1,3)$. The reasons for these disparities in treatment response remain unclear. Prior studies have shown that the biotransformation of MTX is altered in germ-free and microbiome- 